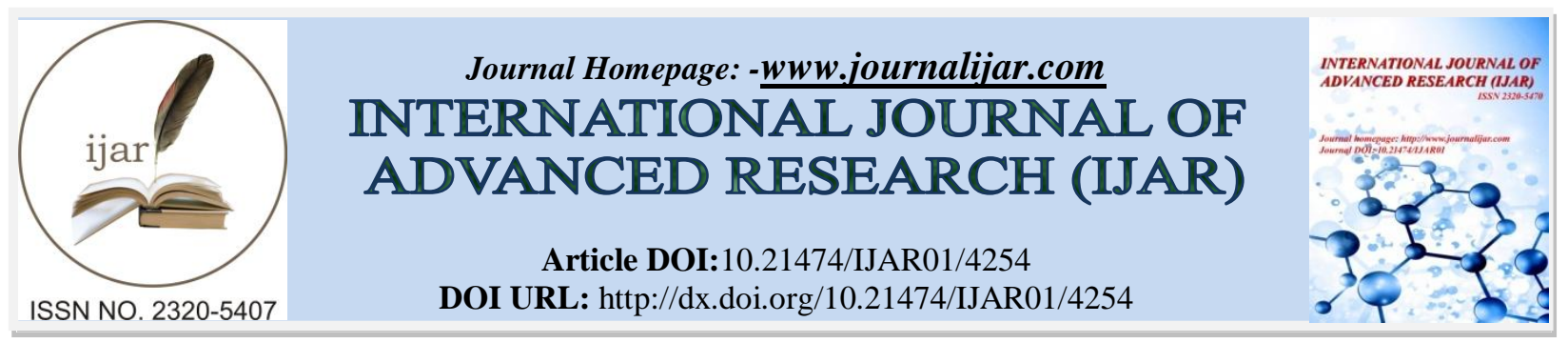

RESEARCH ARTICLE

\title{
ROLE AND ACCURACY OF COMPUTED TOMOGRAPHY GUIDED FNAC OF THORACIC LESION.
}

\author{
Kshama Tiwari ${ }^{1}$ and Kshitij Tewari ${ }^{2}$, \\ 1. Assistant Professor, Era's Lucknow Medical College and Hospital. \\ 2. General Physician, Vivekanand Hospital, Varanasi.
}

\section{Manuscript Info}

Manuscript History

Received: 26 March 2017

Final Accepted: 29 April 2017

Published: May 2017

Key words:-

CT guided FNAC, lung, thoracic mass lesions, bronchogenic malignancies, spinal needle.

\section{ABSTRACT}

Background:- Computed tomography (CT)-guided fine needle aspiration cytology (FNAC) is regarded as a rapid, safe, and accurate diagnostic tool in examining thoracic mass lesions.

Aims: To assess the role of CT-Guided FNAC in thoracic mass lesions, to analyze the results, and to compare the results with other studies.

Materials and Methods: Fifty-five patients were studied over a period of one year (Sep 2011 to Oct 2012) for their age, sex, radiological findings and cytological diagnoses.

Results: Sensitivity of CT guided FNAC in our study was found to be $92.5 \%$ and specificity as $100 \%$. Diagnostic accuracy of CT guided FNAC was quite high at $94.2 \%$. Positive Predictive Value was $100 \%$ and Negative Predictive Value, $80 \%$

Conclusion: CT guided trans-thoracic needle aspiration cytology using a 22 gauge spinal needle is a highly sensitive and specific technique with a good diagnostic accuracy and can be used safely as an outpatient procedure in the diagnosis of thoracic lesions.

Copy Right, IJAR, 2017,. All rights reserved.

\section{Introduction:-}

Diagnostic cytology is the science of interpretation of cells that are exfoliated from epithelial surfaces or removed from various tissues. ${ }^{1}$ Percutaneous trans thoracic fine needle aspiration cytology of lung is a well established method in the cytological diagnosis of thoracic lesions. Computed Tomography guided Fine Needle Aspiration Cytology has become the first line of diagnostic procedure in diagnosing lung malignancies and confirming metastasis. $^{2,3}$ Trans thoracic fine needle aspiration cytology procedure is quite effective as well as accurate. Computed Tomography guidance permits fine needle aspiration cytology of nearly all lesions that are visible on computed tomography scan, regardless of their size or position. ${ }^{4}$

Needle placement in small pulmonary lesions or deep mediastinal nodes can be accurately determined with C.T. \& vascular and cardiac structures are well demonstrated \& safely avoided. ${ }^{\mathbf{5}}$ Pneumothorax, hemorrhage, chest pain and hemoptysis are usually encountered complications but a very few cases require active management. Thoracic lesions encompasses all the lesions of lung, mediastinum, hilar lymph node, thoracic vertebrae, para spinal soft tissue and pleura and each compartment display variety of lesions including congenital malformations, inflammatory lesions, benign and malignant neoplasms. Inflammatory/non neoplastic lesions include acute inflammatory lesions (abscess), granulomatous inflammation caused by Mycobacterium bacilli and also by other specific fungal infections and other nonspecific chronic inflammatory lesions caused by several pathogens. Whereas in neoplastic pathologies 
bronchogenic malignancies are the most concerning lesions which are further subtyped according to the approximate incidence rates as: Squamous cell carcinoma (31\%), adenocarcinoma including bronchioloalveolar carcinoma (30\%), small cell carcinoma (18\%), large cell carcinoma (9\%), carcinoid tumour (1\%) and adenosquamous carcinoma $(2 \%)^{6}$.

\section{Material And Methods:-}

This study is a hospital based prospective study \& carried over a period of one year (September 2011 to October 2012).

\section{Inclusion criteria:-}

- Patients with chest lesions.

- Patients who are cooperative \& able to hold breath.

- Patients who have no bleeding tendency or coagulopathy.

\section{Exclusion criterion:-}

- Patients not able to hold breath

- Patients having severe COPD.

- Patients having bleeding disorders.

- Patients having pulmonary artery hypertension.

- Patients having contralateral pneumenectomy.

\section{Investigations prior to aspiration:-}

- Relevant investigations including BT, PT and INR etc. has to be done.

- Plain \& contrast C.T. of chest is to be done prior to C.T. guided aspiration.

C.T. guided FNAC is carried out as an outpatient procedure after explaining the risks and benefits and obtaining informed consent in every case. First, an axial scan of area of interest is done to locate the lesion; the best approach (supine or prone) is judged and the skin puncture site is marked with a radio opaque marker. After cleaning and draping, local anesthetic agent (2\% xylocaine) is infiltrated at the site of puncture. The 22-gauge spinal needle is then inserted during suspended respiration, directing the tip of needle towards the lesion. With the tip of the needle located in the outer edge of the lesion, a repeat slice of the area of interest is taken to check the exact position of its tip. The stylet is then withdrawn $2-3 \mathrm{~cm}$ and the needle is advanced into the mass with a rotating motion during suspended respiration, so that its tip lies within the target lesion. 20-ml syringe is attached to the needle's hub and the plunger is pulled back, and during continued hard suction, the needle is jiggled to free material from the lesion to the needle's lumen. The aspirate is smeared on slides and fixed in $95 \%$ alcohol for hematoxylin \& eosin staining or papanicolaou staining for cytological evaluation. A repeat slice in the area of interest is taken to rule out pneumothorax. If any amount of pneumothorax developed, patient is kept under observation for 24 hours and a chest x-ray PA view is done after 24 hours to rule out any subsequent development of pneumothorax. In case no complication arose, patient is discharged.

\section{Results:-}

Table 1:- Distribution Of Studied Cases According To Age And Sex

\begin{tabular}{|c|c|c|c|}
\hline \multirow{2}{*}{ Age (Yrs) } & \multicolumn{2}{|c|}{ Sex } & Total \\
\cline { 2 - 4 } & Male & Female & 3 \\
\hline$<20$ & 2 & 1 & $(5.5 \%)$ \\
\hline $20-29$ & $(4.9 \%)$ & $(7.1 \%)$ & 4 \\
& 4 & 0 & $(7.3 \%)$ \\
\hline $30-39$ & $(9.8 \%)$ & $(0.0 \%)$ & 3 \\
& $(0.0 \%)$ & 3 & $(5.5 \%)$ \\
\hline $40-49$ & 10 & $(21.4 \%)$ & 12 \\
& $(24.4 \%)$ & $21.8 \%)$ \\
\hline $50-59$ & 9 & $(14.3 \%)$ & $(212$ \\
& $(20.0 \%)$ & $(21.4 \%)$ & $(21.8 \%)$ \\
\hline
\end{tabular}




\begin{tabular}{|c|c|c|c|}
\hline $60-69$ & 11 & 5 & 16 \\
& $(26.8 \%)$ & $(35.7 \%)$ & 5 \\
\hline \multirow{2}{*}{$70+$} & 5 & 0 & $(29.1 \%)$ \\
\cline { 2 - 4 } & $(12.2 \%)$ & 14 & 55 \\
\hline Total & 41 & 48.00 & 50.40 \\
\hline Mean & 51.22 & $( \pm 15.546)$ & $( \pm 16.110)$ \\
\hline
\end{tabular}

$P>0.005$

This study was based on examination of 55 patients. Table 1 shows distribution of studied cases according to their age and sex. Among all studied 55 cases, 41 were male and the remaining 14 were female. The ratio of male to female was 2.93:1. A gender wise profiling of the patients' age revealed that the mean age was $51.22( \pm 16.40)$ years for the male and $48.00( \pm 15.55)$ years for the female. The age group of the patients in the study ranged from 16 to 80 years. Maximum number of patients (40) was in the age group of 40-69 years, accounting for $72.73 \%$ of total sample; highest share (29.10\%) in age group of 60-69 years. The trend was observed both for male and female. 5 of the patients were $70+$, all male. 3 of the patients were in the age group of 11-20 years.

Table 2:- Distribution Of Lesions Between Non Neoplastic And Neoplastic

\begin{tabular}{|c|c|c|c|}
\hline Site & Non Neoplastic & Neopalstic & Total \\
\hline Lung & 5 & 30 & 35 \\
\hline Mediastinum & 2 & 6 & 8 \\
\hline Hilar Region & 1 & 1 & 2 \\
\hline Pleura & 0 & 2 & 2 \\
\hline Thoracic Vertebra & 2 & 1 & 3 \\
\hline Paraspinal Region & 1 & 1 & 2 \\
\hline Total & 11 & 41 & 52 \\
$(21.15 \%)$ & $(78.85 \%)$ & $(100 \%)$ \\
\hline
\end{tabular}

Table 2 shows site wise distribution of all cytologically proven 52 lesions between non -neoplastic and neoplastic as rest 3 cases remain cytologically in-conclusive because of insufficient material. Out of 52 lesions, 41 (78.85\%) were neoplastic and $11(21.15 \%)$ non-neoplastic. In non neoplastic lesions; 5 were from lung, 2 each from mediastinum \& thoracic vertebrae and one each from hilar and paraspinal soft tissue regions. And in 41 neoplastic lesions majority $(\mathrm{n}=30,73 \%)$ were from lung, 6 from mediastinum, 2 from pleura and one each from hilar, thoracic vertebrae \& paraspinal soft tissue regions. Thus, it was seen that neoplastic lung lesions were the dominant of all thoracic lesions. The non-neoplastic lesions, studied were of types acute inflammatory lesion (organized abscess), chronic non-specific inflammatory lesion, tubercular granulomatous lesion and haematoma. 
Table 3:- Distribution Of Various Neoplastic Lesions

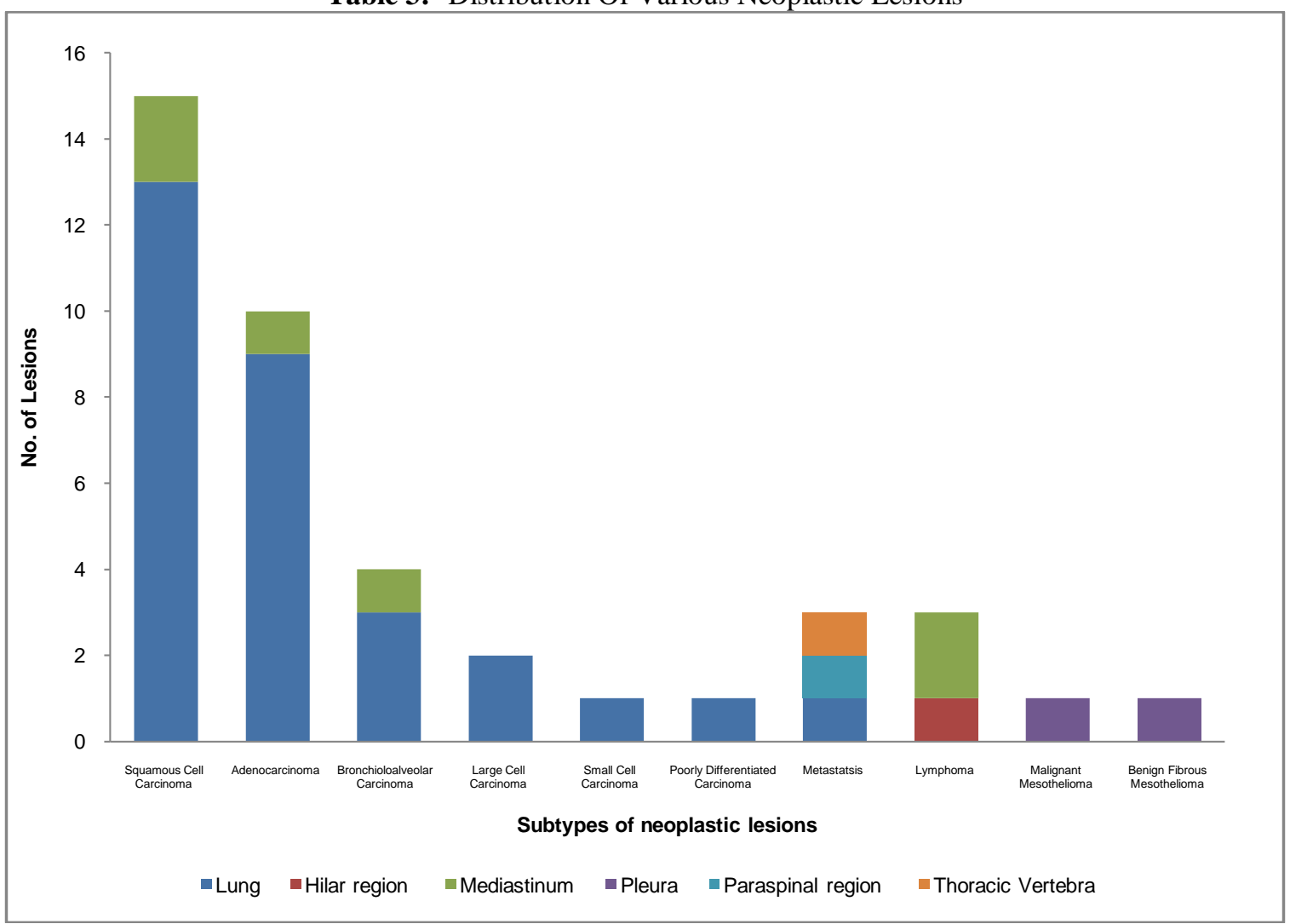

The site wise distribution of specific neoplastic lesions as diagnosed during our study is tabulated above in table 03 . Malignant lesions, were predominant, accounting for $97.56 \%$ in which bronchogenic malignancies were the most common. In bronchogenic malignancies, 'squamous cell carcinoma' was the most common type accounting for $13(44.82 \%)$ cases out of total 29 followed by 'adenocarcinoma' with nine cases (31.03\%), and 'bronchioloalveolar carcinoma', accounting for three cases $(10.34 \%)$. Two cases were of 'large cell type' $(6.67 \%)$, one each of 'small cell carcinoma' (3.45\%) and 'poorly differentiated carcinoma' $(3.45 \%)$. There was one case $(3.3 \%)$ of metastatic deposits from a known patient of breast carcinoma.

Among six mediastinal lesions, two were diagnosed for squamous cell carcinoma, one each for adenocarcinoma \& bronchioloalveolar carcinoma and two cases were diagnosed as non hodgkin lymphoma.Two cases pertained to pleural lesions, one was benign fibrous mesothelioma and the other malignant mesothelioma. In paraspinal region, metastatic deposits was found from a known case of carcinoma stomach (adenocarcinoma). The neoplastic lesion from hilar region was diagnosed to be lymphoma and from thoracic vertebral region, metastatic deposits from bronchogenicmalignancy (adenocarcinoma).

Table 4:- Validity Parameters Of Studied Cases In The Study

\begin{tabular}{|l|c|}
\hline \multicolumn{1}{|c|}{ Diagnosis } & Number Of Cases \\
\hline True Positive & 37 \\
\hline True Negative & 12 \\
\hline False Positive & 0 \\
\hline False Negative & 3 \\
\hline Sensitivity & $92.5 \%$ \\
\hline Specificity & $100 \%$ \\
\hline Positive Predictive Value & $100 \%$ \\
\hline Negative Predictive Value & $80.0 \%$ \\
\hline Diagnostic Accuracy & $94.2 \%$ \\
\hline
\end{tabular}


As various validity parameters shown in table 04 gives sensitivity of C.T. guided FNAC to be $92.5 \%$ and specificity as $100 \%$. Diagnostic accuracy in our study was calculated to be quite high at $94.2 \%$. Positive predictive value was $100 \%$ and negative predictive value, $80 \%$.

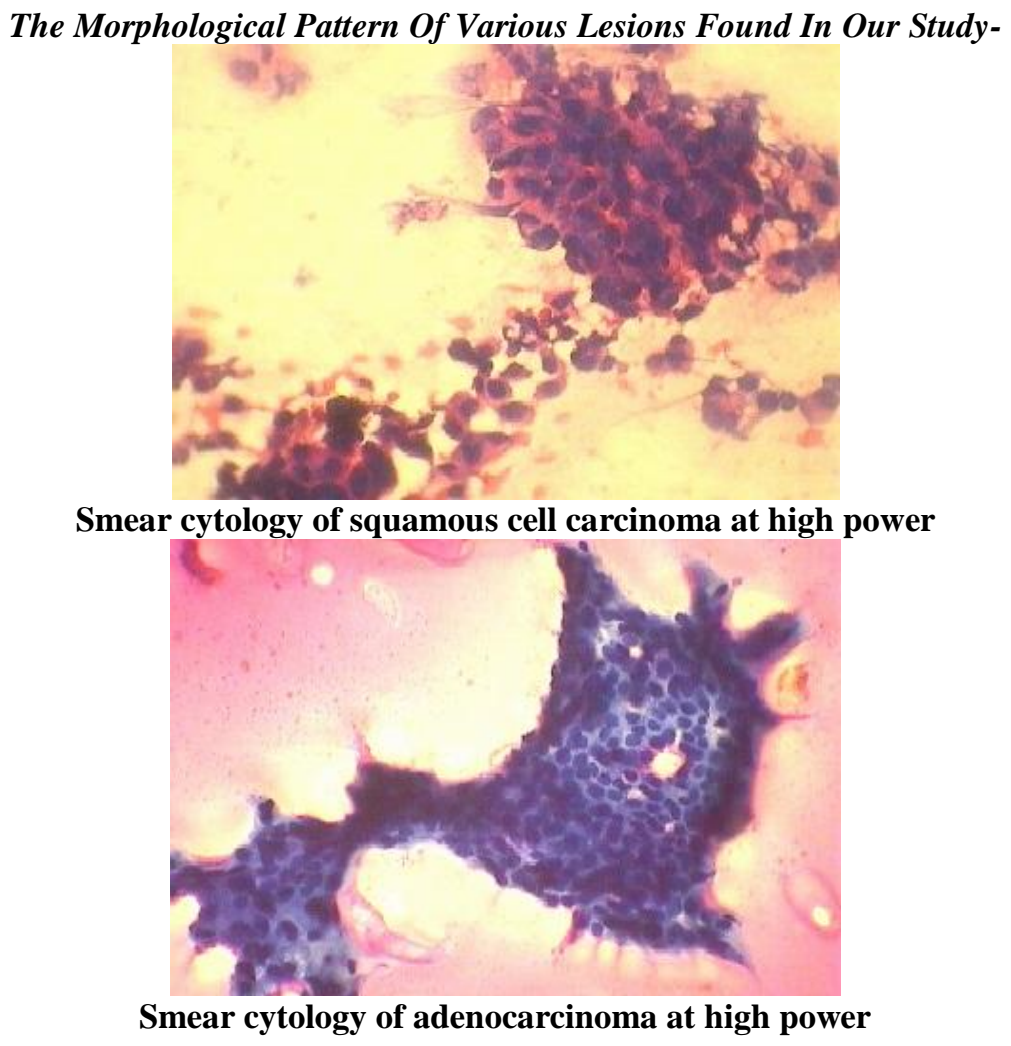

\section{Discussion:-}

In the present study, out of 55 cases 41 were men (74.5\%) and 14 were women $(25.45 \%)$ with a male : female ratio of $2.9: 1$, which was quite comparable to studies by Saha A et al ${ }^{7}$ where male were $78.9 \%$, $\mathrm{Sarkar}_{\mathrm{RN}}$ et $\mathrm{al}^{8}(77 \%$ male) and Jayashankar et al $^{9}(70 \%)$. However greater male ratio $(85 \%)$ was seen in study by Mukherjee $\mathrm{S}$ et al ${ }^{10}$ and lower by Gangopadhyay $\mathrm{M}$ et $\mathrm{al}^{11}(59.8 \%)$ and Singh JP et $\mathrm{al}^{12}(52 \%)$. This male predominance has been attributed to higher incidence of tobacco smoking behaviour among males. The peak age of incidence (60-69 years) in the study was observed to be same as that of the peak age of incidence in two other studies done by Jayashankar et al ${ }^{9}$ (60-69 years) and Basnet et $\mathrm{al}^{13}$ (60-69 years). However, this peak age of incidence was a decade more than that documented in a study by Saha $\mathrm{A}_{\text {et }} \mathrm{al}^{7}$, in which peak age of incidence was in the range of 51-60 years. Most of the patients in this study were in the range of $40-70$ years which was similar to the study done by Mukherjee $\mathrm{S}$ et al ${ }^{10}$ (40-70 years). The mean age of presentation was $51( \pm 16.4)$ years which was almost same as that of $52( \pm 15)$ years which was mean age of presentation of a study conducted by Kalhan $\mathrm{S}$ et al ${ }^{14}$. The mean age of presentation recorded by Saha A et $\mathrm{al}^{7}$ (56.8 years), Gangopadhyay M et al ${ }^{11}$ (58.7 years), and Singh JP et al ${ }^{12}$ (56.4 years) were also almost similar to that of our study. Wallace et al ${ }^{15}$ documented a slightly higher mean age of presentation at 61.3 years. Majority of cases in this study were from lung parenchyma $(67.27 \%)$. This was similar to the studies done by Singh JP et al ${ }^{12}(64.7 \%)$ and Sarkar RN et al ${ }^{8}(67 \%)$. However greater share of studied lesions came from lung in the studies conducted by Rangaswamy et $\mathrm{al}^{16}(81.9 \%)$, Basnet et al ${ }^{13}(91 \%)$, Jayashankar et al ${ }^{9}$ (92\%), Kalhan S et $\mathrm{al}^{14}(92 \%)$ and Saha $\mathrm{A}^{4} \mathrm{al}^{7}(94.7 \%)$. Of the remaining lesions second most common site of affection was mediastinum (16.4\%) followed by thoracic vertebrae $(5.5 \%)$, hilar $(3.6 \%)$, pleural $(3.6 \%)$ and paraspinal $(3.6 \%)$ region.

In our study among cytologically diagnosed 52 cases, 40 were diagnosed as malignant and rest benign. The percentage of malignancy was at $77 \%$ had similarity in findings by Kalhan S et al ${ }^{14}$ (76.1\%), Gangopadhyay M et $\mathrm{al}^{11}(78.8 \%)$ and Singh JP et $\mathrm{al}^{12}(81.80 \%)$. Less percentage of malignancy was diagnosed in studies by Basnet et al ${ }^{13}$ .$(62 \%)$, Sarkar $\mathrm{RN}$ et al ${ }^{8}(65 \%)$ and Jayashankar et $\mathrm{al}^{9}(68.3 \%)$. Inference of cytologically diagnosed 52 cases 
showed that $41(78.9 \%)$ were neoplastic and $11(21.2 \%)$ non neoplastic. Similar observations were also recorded in other studies, like Rangaswamy et $\mathrm{al}^{16}$ where $65.2 \%$ lesions were neoplastic and $32 \%$ were non-neoplastic. Out of 11 non neoplastic lesions; 5 were from lung, 2 each from mediastinum \& thoracic vertebrae and one each from hilar and paraspinal regions. Among pulmonary parenchymal lesions; acute suppurative inflammatory lesions were the most common followed by chronic non specific inflammatory lesions. In both mediastinum and thoracic vertebra, one lesion each of abscess and chronic non specific inflammation was found. In hilar region there was a single case of tubercular granulomatous lesion and one lesion of haematoma was found in paraspinal region.

Among neoplastic lesions, the malignant lesions were predominant accounting for $97.56 \%$ which was similar to the studies by Rangaswamy et $\mathrm{al}^{16}(94.23 \%)$ and Singh JP et $\mathrm{al}^{12}(81.8 \%)$. This indicates that the usefulness of TTFNAC is limited in benign lesions. One of the reason behind this fact is that clinicians do not advise C.T. guided FNAC for benign lesions and also the yield for specific benign lesions is low. Bronchogenic malignancies constituted the largest group among neoplastic lesions accounting for 72.5\%; observation comparable to other study done by Kalhan $\mathrm{S}$ et $\mathrm{al}^{14}(77.2 \%)$. Amongst bronchogenic malignancies prevalence of squamous cell carcinoma and adenocarcinoma was found to be $44.8 \%$ and $31.0 \%$ respectively which was comparable to a study done by Saha A et al where prevalence of squamous cell carcinoma and adenocarcinoma was $42.6 \%$ and $29.6 \%$ respectively. This finding was also comparable to studies done by Basnet et $\mathrm{al}^{13}$ where prevalence of squamous cell carcinoma and adenocarcinoma was $50 \%$ and $28.0 \%$ respectively and Jayashankar et al $^{9}$ with prevalence of squamous cell carcinoma and adenocarcinoma as $51 \%$ and $43.0 \%$ respectively. Thus in most of the studies squamous cell carcinoma was most prevalent bronchogenic malignancy. However, in two studies done by Gangopahyay $\mathrm{M}^{\mathrm{et}} \mathrm{al}^{11}$ and Kalhan $\mathrm{S}$ et $\mathrm{al}^{14}$ prevalence of adenocarcinoma was found to be more than that of squamous cell carcinoma. In the present study bronchioloalveolar carcinoma (10.3\%) was the third most prevalent carcinoma type, followed by large cell type $(6.85 \%)$. The prevalence of small cell carcinoma and poorly differentiated carcinoma was equal and of $3.44 \%$ each. This pattern of prevalence was similar to the study done by Rangaswamy et al ${ }^{16}$ and Sing JP et al. $^{12}$

There were three cases of metastatic malignancy, one in lung which was from known case of carcinoma breast , other in paraspinal region, from known case of carcinoma stomach and third was in thoracic vertebrae from a known case of bronchogenic malignancy . One case each of benign and malignant mesothelioma was also seen in the study. Incidence of pleural lesions was found low in our study, which was comparable to other studies like Rangaswamy et $\mathrm{al}^{16}$ and Kalhan $\mathrm{S}$ et al. ${ }^{14}$

\section{Comparison Of Validity Parameters Of Various Studies With That Of The Present Study:-}

Our study exhibited $94.2 \%$ 'diagnostic accuracy', which was on higher side of reported accuracies in range of 66 to $97 \%$. Similar diagnostic accuracy of $96.3 \%$ was recorded by Rangaswamy et al ${ }^{16}$, $96 \%$ by Sarkar RN et al ${ }^{8}$ and $94.7 \%$ by Basnet et al. ${ }^{13}$ however lower accuracies were observed by Kalhan S et al $^{14}(70.8 \%)$, Mukherjee $\mathrm{S}$ et al ${ }^{10}$ $(85.3 \%)$ and Gangopadhyay $\mathrm{M}$ et al ${ }^{11}(85.8 \%)$. Sensitivity was found to be $92.5 \%$, suggesting high usefulness of CT guided FNAC in diagnosis of malignancy of tumors. Sensitivity of present study was comparable to findings by Singh JP et $\mathrm{al}^{12}(92.6 \%)$, Kalhan S et al ${ }^{14}(93.20 \%)$, Rangaswamy et al ${ }^{16}(93.33 \%)$, Saha $\mathrm{A}^{\text {et }} \mathrm{al}^{7}(94.7 \%)$. Better sensitivity was recorded by Gangopadhyay $\mathrm{M}$ et $\mathrm{al}^{11}(96 \%)$ and Mukherjee $\mathrm{S}$ et $\mathrm{ll}^{10}(97.7 \%)$ and lower sensitivity were recorded by Jayashankar et $\mathrm{al}^{9}(84 \%)$ and Basnet et $\mathrm{al}^{13}(88 \%) .100 \%$ specificity in this study was comparable to studies done by Singh JP et $\mathrm{al}^{12}$, Kalhan $\mathrm{S}$ et $\mathrm{al}^{14}$, Rangaswamy et $\mathrm{al}^{16}$, Sarkar RN et $\mathrm{al}^{8}$ and Mukherjee $\mathrm{S}$ et al ${ }^{10}$. Lower specificity at $76 \%$ was recorded by Jayashankar et al ${ }^{9}$ and at $84 \%$ by Basnet et al. ${ }^{13}$ Positive predictive value of our study was $100 \%$ which was similar to that of found in studies by Singh JP et al ${ }^{12}$ and Sarkar RN et al ${ }^{8}$ and negative predictive value was found to be $80 \%$ which was almost comparable to that found in studies done by Singh JP et $\mathrm{al}^{12}(75 \%)$ and Basnet et $\mathrm{al}^{13}(81 \%)$. Thus the validity parameters of our study showed that the cytological diagnosis was better than diagnosis made by only radiographic findings. Thus Computed tomography guided fine needle aspiration cytology is the one of the best way of providing a diagnosis in inoperable patients and perhaps the greatest value to the clinician.

\section{Conclusion:-}

Diagnostic accuracy of C.T. guided trans thoracic fine needle aspiration cytology is quite high in determining the malignant etiology of a thoracic lesion so it should preferably be performed early in the diagnosis of thoracic lesions, especially in bronchogenic malignancies where early diagnosis and resection remain the best chances of patient survival. Thus, we conclude that C.T. guided trans thoracic fine needle aspiration cytology using a 22 gauge spinal needle is a highly sensitive and specific technique with a good diagnostic accuracy and can be used safely as an outpatient procedure in the diagnosis of thoracic lesions. 


\section{Bibiliography:-}

1. Manual For Cytology, National Cancer Control Programme, Mh \& Fw, Govt Of India, November 2005.

2. Orell Sr Sterret Gf, Walters Mn (1999) Manual And Atlas Of Fine Needle Aspiration Cytology. Third Edition. Edinburg, London, Churchil Livingstone.

3. Richard M. Demay (1996) : The Art And Science Of Cytopathology: Exfoliative Cytology, Ascp Press, American Society Of Clinical Pathologists, Chicago.

4. Vansonnenberg E, Casola G, Ho M, Et Al. Difficult Thoracic Lesions: Ct - Guided Biopsy Experience.

5. Herman Pg, Hessel Sj. The Diagnostic Accuracy And Complications Of Closed Lung Biopsies. Radiology 1997; 125:11-14 In 150 Cases. Radiology 1988; 457-461.

6. Pretreatment Evaluation Of Non-Small-Cell Lung Cancer. The American Thoracic Society And The European Respiratory Society. Amer J Respir Crit Care Med 1997; 156: 320-332.

7. Anupama Saha, Kshitish Kumar, Manoj K Choudhuri: Computed Tomography Guided Fine Needle Aspiration Cytology Of Thoracic Mass Lesions: A Study Of 57 Cases An Article, July 2008.

8. Sarker RN, Rabbi Af, Hossain A, Quddus Ma, Chowdhury N, Sarker T, Kumu Fk, Azad Kak: Computed Tomography Guided Transthoracic Fine Needle Aspiration Cytology In The Diagnosis Of Sonographically NonApproachable Intrathoracic Masses- A Study Of 100 Cases; J Dhaka Med Coll. 2011; 20(1): 25-31.

9. E. Jaya Shankar, B. Pavani, Eshwar Chandra, Ravinder Reddy, M. Srinivas, Ashwin Shah: Computed Tomography Guided Percutaneous Thoracic: Fine Needle Aspiration Cytology In Lung And Mediastinum ; Journal Of Cytology \& Histology, Vol. 1.

10. Sumana Mukherjee, Gautam Bandyopadhyay, Aparna Bhattacharya, Ritu Ghosh, Gopinath Barui, Rupam Karmakar: Computed Tomography- Guided Fine Needle Aspiration Cytology Of Solitary Pulmonary Nodules Suspected To Be Bronchogenic Carcinoma: Experience Of A General Hospital; An Article, Dec. 2007.

11. Mimi Gangopadhyay, Indranil Chakrabarti, Nilanjana Ghosh, Amita Giri: Computed Tomography Guided Fine Needle Aspiration Cytology Of Mass Lesions Of Lung: Our Experience, July 2010.

12.JP Singh, L Garg, V Setia: Computed Tomography (Ct) Guided Transthoracic Needle Aspiration Cytology In Difficult Thoracic Mass Lesions - Not Approachable By Usg;14:4:395-400, August 2004.

13. Basnet Sb, Thapa Gb, Shahi R: Computed Tomography Guided Percutaneous Transthoracic Fine Needle Aspiration Cytology In Chest, Masses: Jnma J Nepal Med Assoc. 2008; July - Sep.; 47 (171): 123-7.

14. Shivani Kalhan, Pankaj Sharma, Sonia Charma Sharmila Dudanil, Ts Ramakrishanan, Anupama Chowdhry: Evaluation Of Precision Of Guidance Technique In Image Guided Fine Needle Aspiratory Cytology Of Thoracic Mass Lesions; Journal Of Cytology / January 2012/ Volume 29/ Issue 1.

15. Wallace Mj, Krishnamurthy S, Broemeling Ld, Gupta S, Ahrar K, Morello Fa Et Al. Ct-Guided Percutaneous Fine-Needle Aspiration Biopsy Of Small (Less Than Or Equal To 1cm) Pulmonary Lesions. Radiology 2002; 225:823-828.

16. Maggad Rangaswamy,Togy Thomas Zacharia, Jayshree Krishnamurthy, Gururajprasad Chennakeshaviah, Sunila, Manjunath Gubbanna Vimala:Study Of Computed Tomography-Guided Fine Needle Aspiration Cytology Of Thoracic Lesions; Journal Of Cytology / January 2012/ Volume 29/ Issue1. 